\title{
Discussion on the Important Influence of Western Costumes on Cheongsam from 1920s to 1940s
}

\author{
Liu Yuanyuan \\ Xi'an Academy of Fine Arts, 710065 \\ Keywords: Cheongsam; Western Costumes; Aesthetics; Tailoring \\ Abstract: After the middle and late 1920s, the cheongsam as a Manchu traditional women' \\ clothing has undergone tremendous changes. While gradually improving itself and \\ establishing its dominant position, cheongsam brings Chinese women' clothing into the \\ international market, which has become a milestone in the history of Chinese clothing. The \\ aesthetics brought by Western costumes and the change of tailoring are important \\ motivations.
}

\section{Introduction}

In the nearly 300-year history of the Qing Dynasty, cheongsam has always maintained the general characteristics of Chinese clothing. Its basic shape is straight lines, loose, stable and main lines of the cross. It only changes in small parts such as collars and sleeves and decorative techniques. By the time of the Republic of China, especially after the mid-to-late 1920s, cheongsam broke the clothing tradition of China for thousands of years. It abandoned the method of linear tailoring and the way of flattening, absorbed the characteristics of western costumes, introduced western-style tailoring, and implemented three-dimensional modeling. Cheongsam emphasized the beauty of the human body, and its shape changed from loose and straight to following the human body curve. Cheongsam gradually developed into the most common and important clothing for Chinese women. The lady, girls from respectable families, the intellectual women, the stars, the prostitutes, the civilians, all of them wear cheongsam, and the cheongsam became the "national costume" of women at that time. As one of the most typical transformations in the history of Chinese clothing, its motivation is diversified. Among them, the significant influence of Western costume on aesthetics and clothing technology cannot be ignored.

\section{The Influence of Western Women’ Costumes}

\subsection{Changes of Costume Aesthetics}

Since the establishment of the first concession in Shanghai in 1845, the concession has become a window to show the Chinese people the food, clothing, housing and travel of the West. By the end of the 19th century, there were more than 500,000 Chinese in the concession. In particular, foreign employees in Chinese business banks have become the best intermediary for Western costumes to influence China. The mixed living of Chinese and foreigners has made the Chinese face to face the 
direct influence of Western costumes. This is the description of the people who lives in Shanghai that foreigners wear Western-style women' clothing in the late Qing Dynasty. The charm of "Western Beauty" is to show women' natural bodybuilding, which is far from the image of Chinese women' long-term restrained and even conservative. While the beauty of the female body is gradually recognized, the aesthetics of the costumes are also changing quietly. Therefore, the mixed living of Chinese and foreigners has led people to unconsciously accept another reference for judging women' beauty. It is a powerful promotion of cheongsam to integrate Chinese and Western costumes.

\subsection{Changes of Cheongsam Modeling}

Shanghai, a modern developed city that is a trading port, is more affected by Western costumes. In the 1930s, as the national fashion center, the latest styles of European and American women' clothing were popular only after three or four months, and the costumes were constantly updated to make the cheongsam quickly change its shape. After the popular cheongsam style became popular in Shanghai, the country took Shanghai as an example and emulated. Therefore, Western-style costumes influenced the whole country through Shanghai.

After 1908, Western-style women' clothing began to become more concise, gradually reducing the embroidery, lace and other decorative. This simple style of clothing had influenced the world for more than ten years. After 1918, women' clothing had undergone major changes. The skirt was further shortened, from a few inches above the ankle to the calf, and it was very loose. Women' clothing, especially for girls, has a "boyish" style that is almost entirely straight, with no curved lines. At this time, the cheongsam was still loose and straight, and lower hem was placed between the ankle and the calf, but the whole has become simple.

In the 1930s, Western-style women' clothing began to have feminine characteristics, and the straight outline had disappeared, showing a moving curve. The loose skirt is tight at the waist and hips. The night dress is beautiful with sleeveless, revealing back and even barely revealing to the waist.

And at this time, many Western fashion estheticians have invariably mentioned in their books that clothing design should pay attention to the beauty of body. For example, Knight Dunlab, author of "The Development of Clothing Function" in 1928, proposed that human beings express their inner spirit and external beauty through clothing. In 1929, the founder of the theory of clothing aesthetics, $\mathrm{E} \cdot \mathrm{B} \cdot$ Hurlock published the book of " The Elements of Fashion" . His view is that one of the most important functions of women' clothing is to express the beauty of women' body. In 1930, clothing esthetician J.C. Flugel published the book of "Costume Psychology" in London. His conclusion is very similar to that of Hollock, who believes that clothing should express physical beauty. In addition, Barr, a professor of philosophy at Columbia University in New York, expressed similar views in his book of "Psychological Analysis of Fashion". He once pointed out that clothing design must conform to people's body and carry forward the advantages of different bodies of beauty. Affected by this, in the 1930s, cheongsam absorbed the Western-style tailoring and entered the era of three-dimensional modeling. The cheongsam was divided into front and back pieces, using sleeves. It abandoned the straight line outline and emphasized the female waist with a curve to highlight the beauty of the body. At this time, the cheongsam generously exposed the female arms and legs to fully display the unique charm of women.

The length of the cheongsam is also deeply influenced by Western costumes. After 1921, the popular skirts in the West became shorter and shorter. By 1925, the bottom edge was flush with the knee. And this style has been popular for several years. Affected by it, from the end of the 20th century, the hem of cheongsam began to shorten, and it gradually shorten to the knee and there was 
still a shortening trend. By 1930, the hem was flush with the knee. Then, the bottom of the western-style skirt gradually lowered. By 1930, the skirt of the evening gown had fallen to the ground, and the bottom of the skirt worn during the day was only 10 to 12 inches from the ground. Affected by it, the cheongsam began to grow longer in 1932. Around 1934, the hem was extended to length from the lower leg to ground.

In general, under the influence of Western costumes and Western dress concepts, Chinese and Western clothing cultures are integrated. The Chinese cheongsam has been completed transition from flat to curved, from loose to tight, from sleeveless to sleeved, and then from traditional to modern. Although this effect is relatively one-way.

\section{Introduction of Western-style Costume Technology}

\subsection{Innovation of Tool and Technology}

The birth of the steam engine at the end of the 18th century marked the beginning of the industrial revolution, and the resulting change in production methods enabled the world to move into the mechanized era from the era of handicrafts. When the industrial revolution waved into the East, China was also deeply affected. After the Revolution of 1911, clothing technology began to evolve under the influence of Western and Japanese clothing. In the early years of the Republic of China, especially in Shanghai, where international relations were deep, suits have become more common clothes. There are hundreds of suit shops and thousands of suit employees in the city. The famous women' suit shops in Shanghai, Madame Green House, Bong Street, etc., are the frequent places for ladies and girls to shop new clothes.

Due to the acceptance of Western tailoring and the introduction of garment processing equipment, such as cloth scissors, soldering iron, sewing machine, etc., the garment industry has formed a situation where both Chinese and Western industries coexist, and machine manufacturing and manual production are inclusive. Since then, the change of clothing has accelerated, and the cheongsam has also jumped out of a single mode, with kinds of collar and other complex changes. The design and process technology promote each other, change and innovate, and work together on cheongsam to promote its continuous evolution on a technical level.

\subsection{Development of Production Shops of New Cheongsam}

The design, production and management methods of cheongsam have also changed with the changes of the times. Established in the early 20th century, several famous clothing stores, in keeping with the trend of the times, actively absorb the Western-style tailoring, and promote the development of cheongsam while achieving commercial success.

In 1917, Hongxiang Women' Clothing Store opened in Shanghai. It was the first professional store to run women' fashion at that time. The technology introduces steric cutting and accurate plate making, which can highlight the beauty of the customer and the special beauty of the clothing. And the store sold finished ladies' suits, which was also the first of its kind at the time. The fashion group's choice of Western-style women' clothing has become the forerunner of the transformation of women' clothing such as cheongsam.

In 1924, Han Junfeng of Shenxian County, Hebei Province, established the "Shuangshun Garment Shop" in Beijing, which is famous for its processing of robes, Chinese jackets, cheongsam and other Chinese-style clothing. When the suit "cloth scissors" technology poured into Beijing, "Shuangshun" updated cheongsam on the old-style basis. According to the material texture change, the half-sleeve cheongsam made of velvet and other fabrics was added to enrich the cheongsam styles. Therefore, "Shuangshun" was awarded the title of "Cheongsam King". 
Shanghai's famous tailoring faction "Red Gang” adopted three-dimensional tailoring methods due to the influence of foreign companies. At that time, the store was equipped with model frame for general and special body figures for tailoring.

In 1938, Bai Haishan opened the "Bai Haiji Garment Shop" in Xingkangli, Huaqing Street, Hankou. The store focused on the study of cheongsam styles, design and color and brands, accurately measuring the body and enhancing the expression of the waist curve. With the different fabrics, they can make single, clip cotton and cotton cheongsam that suits every season. Its fine workmanship and accurate body measurement were praised at the time.

Competition in the industry has led to the introduction of Western-style tailoring to attract consumers. They have keenly captured the trend of the aesthetic trend, and at the same time made a useful attempt and innovation in the combination of this aesthetic fashion and traditional Chinese clothing. The efforts of these new cheongsam production shops in the craftsmanship have enabled the cheongsam tailoring method to integrate Chinese and Western styles, which has promoted the ever-changing style of cheongsam and made an important foundation for its popularity in the country.

\section{Conclusion}

In summary, in the unique social background of the West costumes influencing China, the Western costumes entered China, and a new aesthetic approach penetrated into the lives of Chinese people. The aesthetic standards of clothing that have been popular for thousands of years have been gradually challenged because of the involvement of Western-style costumes. The new aesthetic standards of costumes make the earth-shaking changes in cheongsam, which are completely different from the changes in the past. The Chinese clothing represented by cheongsam has since shifted from a self-contained system to being assimilated by international fashion, from a vertical historical inheritance to a horizontal foreign-style fashion. The introduction of Western-style tailoring technology has provided favorable technical support for the continuous updating of cheongsam. The combination of Chinese and Western costume in cheongsam gives it a new life and a new look. In the end, the cheongsam enters the classics and become a model of the combination of Chinese and Western in the history of costumes.

\section{References}

[1] Bao Mingxin Chief Editor, Bao Mingxin, Wu Juan, Ma Li, Yang Shu and Wu Di Edited. "Chinese Cheongsam", Shanghai Culture Press, Shanghai, 1998, p. 11 and 12.

[2] Wang Tao. "Ying Ruan Magazine”, Shanghai Ancient Books Press, Shanghai, 1989, p. 123.

[3] Zhu Peichu edited, Zhu Peichu and Hong Min Drawing, "Modern Western Costume Art", Light Industry Press, Beijing, 1985, p. 6-20.

[4] A. Tol. Wilcox [USA] edited, Zou Erhua and Liu Yuan Co-translation: "Western Costumes", Lijiang Press, Guilin, 1992, p. 268.

[5] Yuan Jieying edited, Shen Zhen translated, "Chinese Cheongsam", China Textile Press, Beijing, 2000, p. 200.

[6] Yuan Jieying edited, Shen Zhen translated, "Chinese Cheongsam", China Textile Press, Beijing, 2000, p. $199-201$. 